\section{Drug trial investigators asked to declare financial interests}

Annabel Ferriman, BMJ

Doctors and scientists who take part in UK clinical trials of new drugs which may later be licensed in the United States will have to declare any financial interests under new regulations issued by the United States Food and Drug Administration (FDA).

The Association of the British Pharmaceutical Industry (ABPI) has told its members, which include most UK pharmaceutical companies, that the new American rules will apply to any trials in the United Kingdom that are included in product marketing applications to the FDA.

The new rules came into force from 2 February in the United States and apply to trials that started before that date and have not yet been completed.

The financial interests that are covered by the new regulations include: payments to investigators that are contingent on the results of a study; any payments that exceed $£ 15600$ (\$25000) including honorariums, consulting fees, and grants to fund ongoing research; any proprietary interest in the products being investigated such as trademarks, patents, copyrights, or licensing agreements; and any significant equity interests in the sponsor. Investigators and their sponsors will also have to certify the absence of any financial interests if none exist. Spouses and dependant children of investigators are included in the arrangements to prevent financial interests being hidden within a family.

"It is only right that investigators should know in advance that financial disclosure will be required," said Dr Richard Tiner, medical director of the ABPI. "It would be inappropriate to have to go back to investigators at a later stage to ask for this information, so we want to make sure everyone is aware of the new regulations."

\section{Upper age limit should be raised for cancer screening}

Caroline White, London

Current age bands for cancer screening in the United Kingdom seem to have been arbitrarily selected and are not based on rational criteria, according to researchers from the Wolfson Institute of Preventive Medicine in London.

The age band is critical to evaluating the effectiveness of screening programmes and for identifying priorities in screening policy, they concluded.

The research team, led by Dr Malcolm Law, used national statistics on the cause of death to plot the incidence of a given cancer against life expectancy and so determine the number of cumulative years of life lost to different cancers at different ages (Journal of Medical Screening 1999;6:16-20).

The study included melanomas, ovarian cancer, and prostate cancer; screening for these cancers is not currently done.

The results indicated that screening would be most effective at saving lives if done around five years before loss of life peaked.

For breast cancer this is at age 55-59 (189 years of life lost per 10000 women a year) and

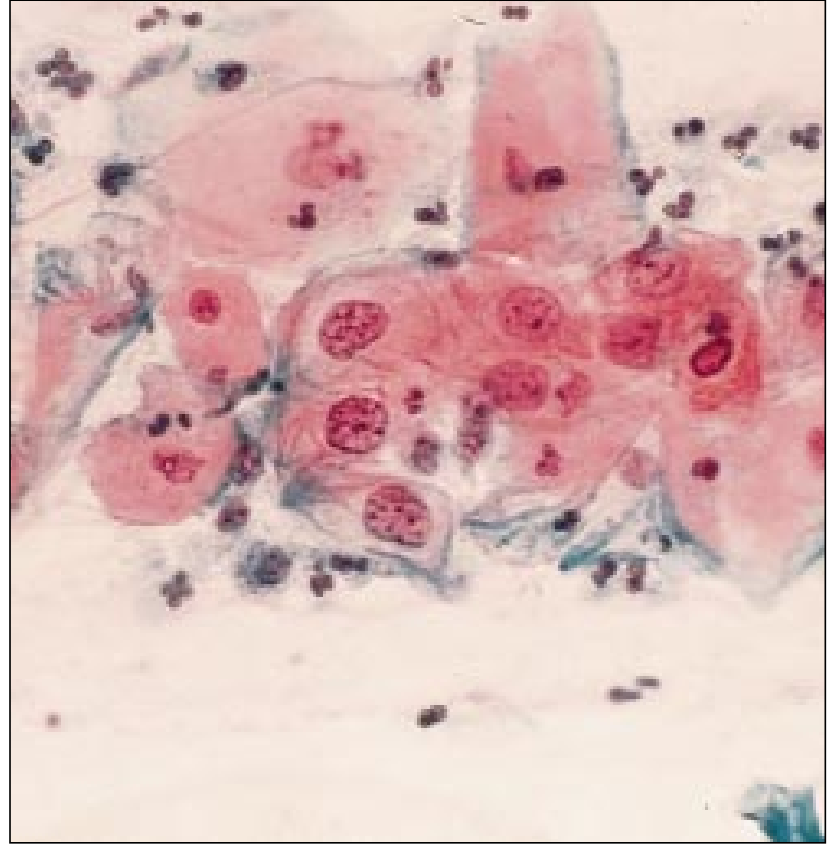

Mild cervical dysplasia: more lives are lost to cervical cancer among women in their $70 \mathrm{~s}$ than women in their $30 \mathrm{~s}$ 50-54 (47 years of life lost per 10000 women).

The research showed that breast and cervical cancer screening offer the most benefit and that extending breast cancer screening to the age of 74 would be more effective than cervical screening at any age.

It also indicated that cervical screening policy should be extended to the age of 69 because more lives are lost to cervical cancer among women in their 70 s than among women for cervical cancer it is at age

\section{UK juniors to be surveyed over action on pay}

Linda Beecham, $B M J$

Representatives of the United Kingdom's 34000 junior hospital doctors have unanimously agreed to survey doctors to find out their views on taking industrial action because of the failure of the pay review body and the health departments to value out of hours work appropriately.

At a meeting of the BMA's Junior Doctors Committee last week angry members called for a new national agreement on out of hours pay and for a publicity campaign on how the current payments compare with those of other professions.

Junior doctors receive only half their basic salary for hours worked beyond 40 if they are on an on call rota, and $70 \%$ of basic salary if they are working a partial shift. This means that a house officer on an annual salary of $£ 16710$ (\$26730) will earn only $£ 4.02$ an hour for work done out of hours. The same rates will apply to the millennium holiday unless pay improves.

The doctors' pay review body has refused to recommend an increase in the rates and this year refused the JDC's request for an antisocial hours supplement of $£ 100$ for weekends. This was despite the BMA's evidence that one in six junior doctors is still working more than 56 hours a week, a limit which should have been introduced for all doctors by the end of 1996.

The committee was also angry at the spin that the Department of Health put on the review body's recommendations. In its press release the department misleadingly quoted maximum earning figures based on a 72 hour working week including 32 compulsory additional duty hours. The JDC's chairman, Mr Andrew Hobart, has asked the health secretary for an apology and a correction; he has had no reply.

If the majority of respondents to the survey support some sort of industrial action, including strike action, the BMA, as the junior doctors' trade union, would have to conduct a ballot among members. 